\title{
Combined effect of glycemic and blood pressure control on diabetic retinopathy among Chinese with type- 2 diabetes mellitus
}

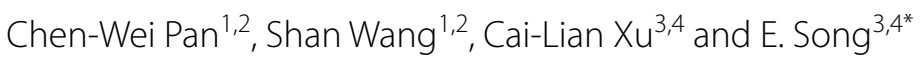

\begin{abstract}
Background: To explore the associations of glycemic and blood pressure (BP) control with diabetic retinopathy (DR), with special focus on whether different combinations of categories of these two interventions are additive.

Methods: A community-based survey including 913 patients with known type-2 diabetes mellitus (T2DM) was conducted in Suzhou, China. Retinal photographs were graded for the presence of DR using the Airlie House classification system. BP and blood hemoglobin A1c ( $\mathrm{HbA1C}$ ) levels were measured by standardized protocols. Binary logistic regression models were established to examine the associations of risk factors with DR.

Results: The overall prevalence of any DR was 18.0\% [95\% confidence interval (95\% CI) 15.5-20.6\%] in this population. Stratified by conventional control thresholds, lower levels of either systolic blood pressure (SBP, $<140 \mathrm{mmHg}$ ) or HbA1C ( $<7.0 \%)$ were not significantly associated with decreased susceptibility to DR, while patients simultaneously with lower $\mathrm{HbA} 1 \mathrm{C}$ and SBP levels demonstrated $43 \%$ reduced likelihood of developing DR [adjusted odds ratio $(\mathrm{OR})=0.57,95 \% \mathrm{Cl} 0.33-0.99, \mathrm{P}=0.045)]$, comparing with those with both higher levels of $\mathrm{HbA1C}(\geq 7.0 \%)$ and SBP $(\geq 140 \mathrm{mmHg})$. Meanwhile, the group achieved intensive HbA1C $(<6.5 \%)$ and SBP $(<120 \mathrm{mmHg})$ control goals were found to have the smallest $O R$, but failed in yielding statistical significance $(P=0.10)$.
\end{abstract}

Conclusions: In this community-based DR screening study of Chinese adults with T2DM, combination but not individual of lower SBP $(<140 \mathrm{mmHg})$ and $\mathrm{HbA1C}(<7.0 \%)$ levels, were suggested to be associated with a significantly reduced likelihood of having DR.

Keywords: Diabetic retinopathy, Type-2 diabetes mellitus, Blood pressure, Glucose

\section{Background}

It is projected that there would be more than 400 million individuals with type 2 diabetes mellitus (T2DM) worldwide by the year 2030 [1], most of whom will die or be disabled as a consequence of diabetic vascular complications [2,3]. Diabetic retinopathy (DR) is a major microvascular complication of T2DM. Globally, DR accounts for about $5 \%$ of all blindness, affecting 2 million people throughout the world $[4,5]$. In China, the population prevalence of any DR, non-proliferative DR

\footnotetext{
*Correspondence: songesuda@163.com

${ }^{3}$ Lixiang Eye Hospital of Soochow University, 200 East Gan Jiang Road, Suzhou 215123, China

Full list of author information is available at the end of the article
}

and proliferative DR was estimated to be 1.14, 0.90 and $0.07 \%$, respectively [6]. If no prompt action is taken, the estimated number of people affected by DR will increase from 126 million in the year 2010 and to 191 million by the year 2030 [7]. DR is the also the leading cause of blindness in working-aged adults, placing a heavy burden on society and leading to loss of human and financial resources [8-14]. Therefore it is of utmost importance to prevent this major diabetes complication from a public health perspective.

Elevated glucose and blood pressure (BP) are wellestablished risk factors for diabetes [15]. Both glycemia and BP lowering treatments were documented to reduce the risk of macrovascular and microvascular complications among patients with T2DM [16-19]. Nevertheless, 
lowering glycemia and BP in individuals with T2DM is an area of current controversy, with particular debates surrounding who should be offered therapy and what the glucose/BP targets should be achieved. When it comes to DR, the United Kingdom Prospective Diabetes Study revealed that an intensive compared with a conventional glycemia control policy could reduce the risk of DR [20], while other studies revealed inconsistent results that there was a non-significant trend toward a beneficial effect in the intensive-therapy group with respect to DRin the standard-therapy group [21-25]. A recent metaanalysis of landmark diabetes trials reported that each $10-\mathrm{mmHg}$ decrease in systolic BP (SBP) was associated with a $13 \%$ reduction in the risk of DR; however, when trials were stratified by mean baseline SBP at greater than or less than $140 \mathrm{mmHg}$, the relative risk for DR was not lower in studies with greater baseline SBP [26]. Additionally, regarding therapies to lower glucose and SBP, it remains uncertain whether treatment of either alone is sufficient, or whether, to obtain maximum benefit, both of these risk factors need to be treated simultaneously [27]. Multiple risk factor intervention trials in T2DM has shown that increased benefits can be obtained by targeting several risk factors simultaneously [22, 28, 29], while other studies demonstrated that combined intensive $\mathrm{BP}$ and glycemic control does not produce an additive benefit on microvascular outcomes in T2DM [30, 31]. With regard to the above mentioned conflict findings, it remains unknown as to whether there is a specific threshold at which glycemic and BP control would complement each other multiplicatively in the clinical management of T2DM and DR, or if extremes of each risk factor might mitigate or enhance the benefits of controlling the other.

Diabetes is a major public health concern in the mainland of China, the world's most populous country [32]. We undertook a cross-sectional study in urban communities located in eastern China to explore the associations of glycemic and BP control with DR, with special focus on whether different combinations of categories of these factors are additive.

\section{Methods}

\section{Study design and procedure}

This study was part of the Gusu Diabetic Retinopathy Screening Study on community-dwelling patients who had been previously diagnosed with T2DM in Suzhou located in eastern China. The detailed methodology and some major findings have been described in previous reports [33-35]. In Brief, all T2DM patients registered in the local Center for Disease Control and Prevention were invited to participate in the survey. The diagnosis of diabetes was based on the American Diabetes Association's new diagnostic criterion for undiagnosed diabetes [36].
Totally, 1247 patients were in the sampling frame and 913 took part in the study, giving a response rate of $73.2 \%$. Nonparticipants on average were younger than participants $(P<0.001)$, but there were no gender differences $(P=0.38)$.

The study adhered to the Declaration of Helsinki and ethics approval was obtained from the Institutional Review Board of the Soochow University. Written inform consent was obtained from each participant at the recruitment stage of the study.

\section{Diabetic retinopathy assessments}

The grading of DR was performed on retinal fundus photographs. Two retinal fundus photographs centered at the optic disc and the macula were taken from both eyes using a digital retinal camera (Canon Inc., Japan). The Airlie House classification system of the Early Treatment Diabetic Retinopathy Study were used to grade retinopathy lesions [37]. Ungradable eyes were excluded from analysis.

\section{Measurement and definitions of covariates}

Information regarding socioeconomic status and lifestyle-related factors were collected by questionnaires. Body Mass Index (BMI) was calculated as weight divided by the square of height in meters $\left(\mathrm{kg} / \mathrm{m}^{2}\right)$. Systolic and diastolic BP were recorded using a non-invasive BP monitor (Dinamap, Germany) by trained study nurses during the clinical examination. Non-fasting venous blood samples were collected and sent for biochemistry tests, including the analysis of hemoglobin A1c (HbA1c). Diseases histories such as nephrosis and heart disease were retrieved from health records of the participants. They were diagnosed previously by physicians and we cannot know the exact definitions as different physicians may have different diagnosis of the diseases.

\section{Statistical analysis}

Intensive and standard glucoselowering therapy were defined as target HbA1C lower than $6.5 \%$ and $7.0 \%$, respectively [22]. BP control were usually defined as intensive $(\mathrm{SBP}<120 \mathrm{mmHg})$ or standard $(\mathrm{SBP}<140 \mathrm{mmHg})$ [30]. Therefore, we divided patients into categories based on individual or combined $\mathrm{HbA1C}$ and SBP thresholds: HbA1C (6.5\% and 7.0\%) and SBP (120 and $140 \mathrm{mmHg}$ ), respectively.

Data were summarized using proportions, means-SD, as appropriate. Statistical analyses were performed using SPSS version 11.0 (SPSS Inc., Chicago, IL, USA). Binary logistic regression models were established to examine the associations of risk factors with DR. For multivariate analysis, only age, gender and known risk factors for 
diabetes such as BMI, durations of diabetes, and the presence of hyperlipidemia were adjusted in the model.

\section{Results}

Among the 913 participants in this study, 880 had gradable retinal fundus photograph in at least one eye. Completed data of BP, HbA1C and other covariates were obtained from 719 participants, who included in the data analyses. The mean age of participants included in the analysis was $67.7 \pm 8.3$ years and there were more women than men ( $56 \%$ vs. $44 \%$ ). The mean duration of diabetes was $10.5 \pm 7.1$ years and the mean blood level of HbA1Cwas $7.2 \pm 1.3 \%$. Table 1 demonstrates the prevalence of DR by different variables. The overall prevalence of any DR was $18.0 \%$ [ $95 \%$ confidence interval (95\% CI) $15.5-20.6 \%$ ] in this

Table 1 Clinical features between participants absent and present DR

\begin{tabular}{|c|c|c|c|c|}
\hline Characteristics & Absent $(n=719)$ & Present $(n=158)$ & OR $(95 \% \mathrm{Cl})$ & $P^{*}$ \\
\hline Age & $68.00 \pm 8.24$ & $66.47 \pm 8.37$ & $0.98(0.96-1.00)$ & 0.04 \\
\hline BMI & $24.36 \pm 3.09$ & $23.96 \pm 2.84$ & $0.96(0.9-1.01)$ & 0.14 \\
\hline \multicolumn{5}{|l|}{ Sex } \\
\hline Male & 309 (43.0\%) & $78(49.4 \%)$ & 1.00 (ref) & \\
\hline Female & $410(57.0 \%)$ & $80(50.6 \%)$ & $0.77(0.55-1.09)$ & 0.14 \\
\hline \multicolumn{5}{|l|}{ Education } \\
\hline High school and below & $621(86.4 \%)$ & $136(86.1 \%)$ & 1.00 (ref) & \\
\hline University and above & $98(13.6 \%)$ & $22(13.9 \%)$ & $1.03(0.63-1.70)$ & 0.90 \\
\hline \multicolumn{5}{|l|}{ Live alone } \\
\hline No & 655 (91.1\%) & 142 (89.9\%) & 1.00 (ref) & \\
\hline Yes & $64(8.9 \%)$ & $16(10.1 \%)$ & $1.17(0.66-2.09)$ & 0.59 \\
\hline \multicolumn{5}{|l|}{ Regular tea consumption } \\
\hline No & $353(49.1 \%)$ & $65(41.1 \%)$ & 1.00 (ref) & \\
\hline Yes & $366(50.9 \%)$ & $93(58.9 \%)$ & $1.38(0.97-1.95)$ & 0.07 \\
\hline \multicolumn{5}{|l|}{ Smoking } \\
\hline No & $581(80.8 \%)$ & 119 (75.3\%) & 1.00 (ref) & \\
\hline Yes & $138(19.2 \%)$ & $39(24.7 \%)$ & $1.39(0.93-2.09)$ & 0.11 \\
\hline \multicolumn{5}{|l|}{ Alcohol drinking } \\
\hline No & 645 (89.7\%) & $141(89.2 \%)$ & 1.00 (ref) & \\
\hline Yes & 74 (10.3\%) & $17(10.8 \%)$ & $1.07(0.61-1.86)$ & 0.82 \\
\hline \multicolumn{5}{|l|}{ Nephrosis } \\
\hline Absent & $617(87.2 \%)$ & $133(86.9 \%)$ & $1.00($ ref) & \\
\hline Present & $92(12.8 \%)$ & $20(13.1 \%)$ & $1.09(0.97-1.23)$ & 0.14 \\
\hline \multicolumn{5}{|l|}{ Heart disease } \\
\hline Absent & $507(70.5 \%)$ & $113(71.5 \%)$ & 1.00 (ref) & \\
\hline Present & $212(29.5 \%)$ & $45(28.5 \%)$ & $0.95(0.65-1.39)$ & 0.79 \\
\hline Systolic pressure (mmHg) & $142.65 \pm 18.83$ & $143.75 \pm 19.22$ & $1.00(0.99-1.01)$ & 0.51 \\
\hline Diastolic pressure $(\mathrm{mmHg})$ & $79.8 \pm 10.43$ & $80.2 \pm 9.93$ & $1.00(0.99-1.02)$ & 0.66 \\
\hline Diabetes duration (years) & $10.3 \pm 6.98$ & $11.45 \pm 7.50$ & $1.02(1.00-1.05)$ & 0.07 \\
\hline $\mathrm{HbA1C}(\%)$ & $7.09 \pm 1.27$ & $7.49 \pm 1.57$ & $1.22(1.08-1.38)$ & 0.001 \\
\hline \multicolumn{5}{|l|}{ Hypertension } \\
\hline Absent & $226(31.4 \%)$ & $51(32.3 \%)$ & 1.00 (ref) & \\
\hline Present & $493(68.6 \%)$ & $107(67.7 \%)$ & $0.96(0.67-1.39)$ & 0.84 \\
\hline \multicolumn{5}{|l|}{ Stroke } \\
\hline No & $695(96.7 \%)$ & $151(95.6 \%)$ & 1.00 (ref) & \\
\hline Yes & $24(3.3 \%)$ & $7(4.4 \%)$ & $1.34(0.57-3.17)$ & 0.50 \\
\hline \multicolumn{5}{|l|}{ Hyperlipidemia } \\
\hline Absent & $517(71.9 \%)$ & $114(72.2 \%)$ & 1.00 (ref) & \\
\hline Present & 202 (28.1\%) & 44 (27.8\%) & $0.99(0.67-1.45)$ & 0.94 \\
\hline
\end{tabular}

$D R$ diabetic retinopathy

* $P$ values were got from logistic regression 
population. Older age and longer duration of diabetes was associated with a higher prevalence of DR, and higher $\mathrm{HbA1C}$ levels was significantly associated with an increased likelihood of having DR among T2DM patients [odds ratio $(\mathrm{OR})=1.22, P=0.001$ ]. However, the association between DR and SBP or DBP levels was not significant $(\mathrm{P}=0.89$ for $\mathrm{SBP}$ and $\mathrm{P}=0.90$ for $\mathrm{DBP})$.

Participants were then stratified to categories by conventional thresholds of SBP and HbA1C therapies. As shown in Table 2, there were $46.24 \%$ of patients with SBP levels less than $140 \mathrm{mmHg}$, and $58.08 \%$ of patients with $\mathrm{HbA} 1 \mathrm{C}$ levels less than $7.0 \%$. In multivariate analyses, although lower levels of either SBP or $\mathrm{HbA1C}$ were not significantly associated with decreased risk of DR, combined lower HbA1C and blood pressure levels demonstrated a $43 \%$ reduction in the likelihood of developing DR (adjusted OR $=0.57$, 95\% CI 0.33-0.99, $P=0.045$ ).

In the next step, patients were divided by intensive and standard thresholds (Table 3). Compared with levels of $6.5-6.9 \%$, HbA1C levels lower than $6.5 \%$ did not contribute to significantly decreased risk of DR (adjusted OR $=0.87,95 \%$ CI $0.51-1.47$, $P=0.60$ ). Similarly result was also observed for SBP comparison (adjusted OR $=0.71,95 \%$ CI $0.37-1.38$, $P=0.31 ;<120 \mathrm{mmHg}$ vs. $120-139 \mathrm{mmHg}$ ). At the same time, we also explored whether different combinations of categories of SBP and HbA1C could offer additive benefit. The group with HbA1C level of 6.5$6.9 \%$ and SBP level of $120-139 \mathrm{mmHg}$ was treated as the reference group, patients with the combined lowest HbA1C $(<6.5 \%)$ and SBP $(<120 \mathrm{mmHg})$ levels yielded the lowest OR of 0.38 , but this association was not statistically significant $(P=0.10)$.
Table 3 Associations between DR and different categories of systolic pressure and HbA1C (stratified by conversional and intensive thresholds)

\begin{tabular}{|c|c|c|c|c|c|}
\hline HbA1C (\%) & $\begin{array}{l}\text { SBP } \\
(\mathrm{mmHg})\end{array}$ & $\begin{array}{l}\text { Without } \\
\text { DR } \\
(n=719)\end{array}$ & $\begin{array}{l}\text { With DR } \\
(n=158)\end{array}$ & $\begin{array}{l}\text { OR }(95 \% \\
\mathrm{Cl})^{*}\end{array}$ & $P^{*}$ \\
\hline$<6.5$ & & 243 & 38 & $\begin{array}{c}0.87(0.51- \\
1.47)\end{array}$ & 0.60 \\
\hline $6.5-6.9$ & & 150 & 35 & 1.00 (ref) & \\
\hline \multirow[t]{4}{*}{$\geq 7$} & & 326 & 85 & $\begin{array}{c}1.19(0.74- \\
1.93)\end{array}$ & 0.47 \\
\hline & $<120$ & 75 & 13 & $\begin{array}{c}0.71(0.37- \\
1.38)\end{array}$ & 0.31 \\
\hline & $120-139$ & 236 & 58 & 1.00 (ref) & \\
\hline & $\geq 140$ & 408 & 87 & $\begin{array}{l}0.82(0.56- \\
1.19)\end{array}$ & 0.30 \\
\hline$<6.5$ & $<120$ & 37 & 5 & $\begin{array}{c}0.38(0.12- \\
1.19)\end{array}$ & 0.10 \\
\hline$<6.5$ & $139-120$ & 75 & 16 & $\begin{array}{c}0.73(0.32- \\
1.67)\end{array}$ & 0.46 \\
\hline$<6.5$ & $\geq 140$ & 131 & 17 & $\begin{array}{l}0.58(0.27- \\
1.27)\end{array}$ & 0.18 \\
\hline $6.5-6.9$ & $<120$ & 20 & 3 & $\begin{array}{l}0.53(0.13- \\
2.18)\end{array}$ & 0.38 \\
\hline $6.5-6.9$ & $139-120$ & 48 & 15 & 1.00 (ref) & \\
\hline $6.5-6.9$ & $\geq 140$ & 82 & 17 & $\begin{array}{l}0.52(0.21- \\
1.30)\end{array}$ & 0.16 \\
\hline$\geq 7$ & $<120$ & 18 & 5 & $\begin{array}{l}0.87(0.26- \\
2.86)\end{array}$ & 0.81 \\
\hline$\geq 7$ & $139-120$ & 113 & 27 & $\begin{array}{l}0.74(0.35- \\
1.60)\end{array}$ & 0.45 \\
\hline$\geq 7$ & $\geq 140$ & 195 & 53 & $\begin{array}{l}0.87(0.43- \\
1.77)\end{array}$ & 0.70 \\
\hline
\end{tabular}

$D R$ diabetic retinopathy, SBP systolic blood pressure, OR odds ratio, 95\% CI 95\% confident interval

* Multivariate logistic regression models, adjusted by covariates such as sex, age, body mass index, diabetes duration, and the presence of hyperlipidemia

Table 2 Associations between DR and different categories of SBP and HbA1C (stratified by conversional thresholds)

\begin{tabular}{|c|c|c|c|c|}
\hline Category & Without DR $(n=719)$ & With DR $(n=158)$ & OR $(95 \% \mathrm{Cl})^{*}$ & $P^{*}$ \\
\hline \multicolumn{5}{|l|}{$\mathrm{SBP}(\mathrm{mmHg})$} \\
\hline$\geq 140$ & 408 & 87 & 1.00 (ref) & \\
\hline$<140$ & 311 & 71 & $1.03(0.72-1.46)$ & 0.89 \\
\hline \multicolumn{5}{|l|}{$\mathrm{HbA1C}(\%)$} \\
\hline$\geq 7.0$ & 326 & 85 & 1.00 (ref) & \\
\hline$<7.0$ & 393 & 73 & $0.78(0.55-1.11)$ & 0.17 \\
\hline \multicolumn{5}{|l|}{ Combined } \\
\hline $\mathrm{SBP} \geq 140 \mathrm{mmHg}$ and $\mathrm{HbA} 1 \mathrm{C} \geq 7 \%$ & 195 & 53 & 1.00 (ref) & \\
\hline $\mathrm{SBP}<140 \mathrm{mmHg}$ or $\mathrm{HbA} 1 \mathrm{C}<7 \%$ & 344 & 66 & $0.63(0.38-1.05)$ & 0.08 \\
\hline $\mathrm{SBP}<140 \mathrm{mmHg}$ and $\mathrm{HbA} 1 \mathrm{C}<7 \%$ & 180 & 39 & $0.57(0.33-0.99)$ & 0.045 \\
\hline
\end{tabular}

DR diabetic retinopathy, SBP systolic blood pressure, OR odds ratio, 95\% Cl 95\% confident interval

* Multivariate logistic regression models, adjusted by covariates such as gender, age, BMI, diabetes duration, and presence of hyperlipidemia 


\section{Discussion}

In this community-based DR screening study of Chinese adults with T2DM living in an urban community in eastern China, we found that simultaneously lowering SBP and HbA1C levels than standard thresholds was associated with a significantly reduced likelihood of having DR. The findings suggested that combined standard therapeutic approach of simultaneously improving both blood glucose and BP might confer greater benefit than by treating either alone, which have important implications for the clinical management of DR.

To the best of knowledge, although the main effects of $\mathrm{BP}$ and glycemic control on the risk of diabetic vascular complications such as DR have been extensively investigated [38], the combined effect of these two interventions is less well assessed. Hypertension in type 1 diabetes patients has been shown to significantly increase the risk of proliferative DR in the Wisconsin Epidemiology Study [39]. Another study indicated that each increment of $5 \mathrm{mmHg}$ in night-time systolic and diastolic blood pressure leads to an increase in about $40 \%$ in the risk of DR even in normotensive diabetic individuals [40]. Our study demonstrated that either lowering $\mathrm{HbA1C}$ or $\mathrm{BP}$ levels alone was not related to a significant reduction in the likelihood of having DR but combined lowering the levels of the two resulted in a $43 \%$ reduction in the likelihood of having DR. The magnitude of reduction reached clinical significance and might have important implications for the clinical management of patients with T2DM. Some animal models have demonstrated that combination of diabetes and hypertension lead to early and more severe markers of DR, both functional and morphological. A study on diabetic rats have observed that basement membrane thickness and permeability to serum albumin increased were significantly enhanced when diabetes coexisted with hypertension [41]. Hammes et al. have shown that the frequency of acellular capillaries, a morphological gold-standard marker of DR, was nearly twice as high in diabetic and hypertensive rates as in rats with diabetes only. In this study, hypertension-induced deposition of advanced glycation endproducts-proteins in the retinal vasculature played a central role in the acceleration of diabetic retinopathy by hypertension. Inhibition of advanced glycation endproducts formation by aminoguanidine prevented both accelerated diabetic retinopathy and thrombus formation without affecting hypertension. Therefore, the importance of hypertension in retinal disease was still debatable [42].

Both inflammation and oxidative stress could serve as the underlying mechanism for the observed association of poor BP and glycemic control with DR. Both oxidative stress [43, 44] and inflammation [45] have been strongly implicated in the pathogenesis of DR. It has been shown that hypertension could induce oxidative stress and inflammation [46], which, in turn, contribute to the development of DR. For example, in one animal study, genetic susceptibility of hypertension, before the establishment of full hypertension, was enough to lead to an earlier development of inflammation in the retina in the presence of diabetes [47]. Inflammation and oxidative stress and are closely related. On one hand, oxidative stress could result from the generation of reactive species from the inflammatory cells. On the other hand, oxidative stress may also lead to inflammation by pro-inflammatory gene expression [48]. The simultaneous presence of inflammation and oxidative stress tend to coexist in an inseparable manner in different organs, particularly in the retina [45].

Our study is one of the few studies describing the associations between DR and the combination of HbA1C and SBP levels among T2DM patients, especially in Chinese populations. We had a representative study sample and the use of standardized DR grading protocol also facilitated the comparisons among different studies. There were also some limitations of the study which should be acknowledged. First, the crosssectional design limited our ability to determine the causal effect between exposures and outcomes. The DR status of the patients at the time of diagnosis of hypertension or diabetes or the initiation of antihypertensive or diabetic agents are not clear. It is possible that the grading of DR changes most with intensive treatment strategies. Second, information on other diabetes risk factors, such as psychological stress, unhealthy dietary practices, physical inactivity and patterns of health service utilization were not available in this study, and therefore the possibility of residual confounding in our regression analysis could not be excluded. Third, a single blood pressure measurement may not accurately indicate how blood pressure of the participants had been controlled. Fourth, lipid parameters has been reported to be associated with the presence and development of DR but were not collected in this study. Fifth, the number of participants with vision-threatening DR was small and the study had insufficient power to evaluate associations of different stages DR with glycemic and blood pressure control. Finally, it was found that patients simultaneously achieved intensive HbA1C and SBP control goals had the lowest OR without statistical significance, among different categories of combination of $\mathrm{HbA1C}$ and SBP levels. It may be that the overall sample size was relatively small and some categories were with quite small numbers of patients, and therefore our study may have a lack of statistical power to explore whether there was additional benefit of the combination of intensive therapies compared to 
standard controls. It warrants further investigation, on which field we are continuously working on.

\section{Conclusions}

In summary, simultaneously lowering SBP and HbA1C levels than standard therapy thresholds was significantly associated with a reduced likelihood of having DR among Chinese T2DM patients. Well-designed clinical trials or longitudinal cohort studies are warranted to examine the relationship between the role of combined BP and glycemic control in the pathophysiology of DR among patients with T2DM.

\section{Abbreviations \\ T2DM: type 2 diabetes mellitus; DR: diabetic retinopathy; BP: blood pressure; CDC: Center of Disease Control and Prevention; OR: odds ratio; Cl: confidence interval.}

\section{Authors' contributions}

CWP and SW conducted the statistical analyses and interpretation of data. SW, CLX and ES contributed data collection and interpretation of the data. CWP and ES conceived and designed the study, wrote and revised manuscript. All authors read and approved the final manuscript.

\section{Author details \\ ${ }^{1}$ School of Public Health, Medical College of Soochow University, Suzhou, China. ${ }^{2}$ Jiangsu Key Laboratory of Preventive and Translational Medicine for Geriatric Diseases, Soochow University, Suzhou, China. ${ }^{3}$ Lixiang Eye Hospital of Soochow University, 200 East Gan Jiang Road, Suzhou 215123, China. ${ }^{4}$ Department of Ophthalmology, The First Hospital of Jilin University, Changchun, China.}

\section{Acknowledgements}

Not applicable.

\section{Competing interests}

The authors declare that they have no competing interests.

\section{Availability of data and materials}

The datasets analyzed in this study are available from the corresponding author (E Song, songesuda@163.com) upon reasonable request.

\section{Consent for publication}

Not applicable.

\section{Ethics approval and consent to participate}

The study adhered to the Declaration of Helsinki and ethics approval was obtained from the Institutional Review Board of the Soochow University. Written inform consent was obtained from each participant at the recruitment stage of the study.

\section{Funding}

This study was funded by the Suzhou Science and Technology Bureau (Grant No. SS201426 and Grant No. SS201758), the Science and Technology Department of Jilin Province (Grant No. 20130206059SF), Jiangsu Distinguished Medical Experts Program (No. 2016) and Gusu Health Leading Talent Plan (Grant No. 025). The funders had no role in study design, data collection and analysis, decision to publish, or preparation of the manuscript.

\section{Publisher's Note}

Springer Nature remains neutral with regard to jurisdictional claims in published maps and institutional affiliations.
Received: 12 August 2018 Accepted: 27 September 2018

Published online: 01 October 2018

\section{References}

1. Wild S, Roglic G, Green A, Sicree R, King H. Global prevalence of diabetes estimates for the year 2000 and projections for 2030. Diabetes Care. 2004;27(5):1047-53.

2. Xie X, Xu L, Jonas J, Wang Y. Prevalence of diabetic retinopathy among subjects with known diabetes in China: the Beijing Eye Study. Eur J Ophthalmol. 2009;19(1):91.

3. Liu Z, Fu C, Wang W, Xu B. Prevalence of chronic complications of type 2 diabetes mellitus in outpatients - a cross-sectional hospital based survey in urban China. Health Qual Life Outcomes. 2010;8(1):1.

4. Ruta L, Magliano D, LeMesurier R, Taylor H, Zimmet P, Shaw J. Prevalence of diabetic retinopathy in type 2 diabetes in developing and developed countries. Diabet Med. 2013;30(4):387-98.

5. Klein BE. Overview of epidemiologic studies of diabetic retinopathy Ophthalmic Epidemiol. 2007;14(4):179-83.

6. Song P, Yu J, Chan KY, Theodoratou E, Rudan I. Prevalence, risk factors and burden of diabetic retinopathy in China: a systematic review and metaanalysis. J Glob Health. 2018;8(1):010803.

7. Zheng $\mathrm{Y}, \mathrm{He} \mathrm{M}, \mathrm{Congdon} \mathrm{N}$. The worldwide epidemic of diabetic retinopathy. Indian J Ophthalmol. 2012;60(5):428-31.

8. Tung TH, Shih HC, Chen SJ, Chou P, Liu CM, Liu JH. Economic evaluation of screening for diabetic retinopathy among Chinese type 2 diabetics: a community-based study in Kinmen, Taiwan. J Epidemiol. 2008;18(5):225-33.

9. Cikamatana L, Mitchell P, Rochtchina E, Foran S, Wang JJ. Five-year incidence and progression of diabetic retinopathy in a defined older population: the Blue Mountains Eye Study. Eye (Lond). 2007;21(4):465-71.

10. Clark A, Morgan WH, Kain S, Farah H, Armstrong K, Preen D, Semmens $J B, Y u$ DY. Diabetic retinopathy and the major causes of vision loss in Aboriginals from remote Western Australia. Clin Exp Ophthalmol. 2010;38(5):475-82.

11. Kempen JH, O'Colmain BJ, Leske MC, Haffner SM, Klein R, Moss SE, Taylor $H R$, Hamman RF. The prevalence of diabetic retinopathy among adults in the United States. Arch Ophthalmol. 2004;122(4):552-63.

12. McKay R, McCarty CA, Taylor HR. Diabetic retinopathy in Victoria, Australia: the Visual Impairment Project. Br J Ophthalmol. 2000;84(8):865-70.

13. Wong TY, Klein R, Islam FM, Cotch MF, Folsom AR, Klein BE, Sharrett AR, Shea S. Diabetic retinopathy in a multi-ethnic cohort in the United States. Am J Ophthalmol. 2006;141(3):446-55.

14. Xu J, Wei WB, Yuan MX, Yuan SY, Wan G, Zheng YY, Li YB, Wang S, Xu L, Fu $\mathrm{HJ}$, et al. Prevalence and risk factors for diabetic retinopathy: the Beijing Communities Diabetes Study 6. Retina. 2012;32(2):322-9.

15. Stratton I, Cull C, Adler A, Matthews D, Neil H, Holman R. Additive effects of glycaemia and blood pressure exposure on risk of complications in type 2 diabetes: a prospective observational study (UKPDS 75). Diabetologia. 2006;49(8):1761-9.

16. Gerstein HC, Elgar FJ. Effects of ramipril on cardiovascular and microvascular outcomes in people with diabetes mellitus: results of the HOPE study and MICRO-HOPE substudy. Lancet. 2000;355(9200):253-9.

17. Group UPDS. Tight blood pressure control and risk of macrovascular and microvascular complications in type 2 diabetes: UKPDS 38. BMJ Clin Res. 1998;317(7160):703-13.

18. Patel A, Macmahon S, Chalmers J, Neal B, Woodward M, Billot L, Harrap S, Poulter N, Marre M, Cooper M. Effects of a fixed combination of perindopril and indapamide on macrovascular and microvascular outcomes in patients with type 2 diabetes mellitus (the ADVANCE trial): a randomised controlled trial. Neth Heart J. 2007;370(1):829-40.

19. Soltesz G. Diabetes atlas. 3rd ed. 2006.

20. UK Prospective Diabetes Study (UKPDS) Group. Intensive blood-glucose control with sulphonylureas or insulin compared with conventional treatment and risk of complications in patients with type 2 diabetes (UKPDS 33). Lancet. 1998;352(9131):837-53.

21. Group AC. Intensive blood glucose control and vascular outcomes in patients with type 2 diabetes. N Engl J Med. 2008;2008(358):2560-72.

22. Zoungas S, De Galan BE, Ninomiya T, Grobbee D, Hamet P, Heller S, MacMahon S, Marre M, Neal B, Patel A. Combined effects of routine blood 
pressure lowering and intensive glucose control on macrovascular and microvascular outcomes in patients with type 2 diabetes new results from the ADVANCE trial. Diabetes Care. 2009;32(11):2068-74.

23. Duckworth W, Abraira C, Moritz T, Reda D, Emanuele N, Reaven PD, Zieve FJ, Marks J, Davis SN, Hayward R. Glucose control and vascular complications in veterans with type 2 diabetes. N Engl J Med. 2009;360(2):129-39.

24. Ismail-Beigi F, Craven T, Banerji MA, Basile J, Calles J, Cohen RM, Cuddihy R, Cushman WC, Genuth S, Grimm RH. Effect of intensive treatment of hyperglycaemia on microvascular outcomes in type 2 diabetes: an analysis of the ACCORD randomised trial. Lancet. 2010;376(9739):419-30.

25. Boussageon R, Bejan-Angoulvant T, Saadatian-Elahi M, Lafont S, Bergeonneau C, Kassaï B, Erpeldinger S, Wright JM, Gueyffier F, Cornu C. Effect of intensive glucose lowering treatment on all cause mortality, cardiovascular death, and microvascular events in type 2 diabetes: meta-analysis of randomised controlled trials. BMJ. 2011;343:d4169.

26. Emdin CA, Rahimi K, Neal B, Callender T, Perkovic V, Patel A. Blood pressure lowering in type 2 diabetes: a systematic review and meta-analysis. JAMA. 2015;313(6):603-15.

27. Ramsay LE, Williams B, Johnston GD, Macgregor GA, Poston L, Potter JF, Poulter NR. British Hypertension Society guidelines for hypertension management 1999: summary. BMJ Clin Res. 1999;319(7210):630-5.

28. Gaede P, Vedel P, Larsen N, Jensen GV, Parving HH, Pedersen O. Multifactorial intervention and cardiovascular disease in patients with type 2 diabetes. N Engl J Med. 2003;348(5):383-93.

29. Gæde P, Lund-Andersen H, Parving H-H, Pedersen O. Effect of a multifactorial intervention on mortality in type 2 diabetes. N Engl J Med. 2008:358(6):580-91.

30. Ismailbeigi F, Craven TE, O'Connor PJ, Karl D, Callesescandon J, Hramiak I, Genuth S, Cushman WC, Gerstein HC, Probstfield JL. Combined intensive blood pressure and glycemic control does not produce an additive benefit on microvascular outcomes in type 2 diabetic patients. Kidney Int. 2012;81(6):586-94.

31. Margolis KL, O'Connor PJ, Morgan TM, Buse JB, Cohen RM, Cushman WC, Cutler JA, Evans GW, Gerstein HC, Grimm RH. Outcomes of combined cardiovascular risk factor management strategies in type 2 diabetes: the ACCORD randomized trial. Diabetes Care. 2014;37(6):1721-8.

32. Yang W, Lu J, Weng J, Jia W, Ji L, Xiao J, Shan Z, Liu J, Tian H, Ji Q, et al. Prevalence of diabetes among men and women in China. N Engl J Med. 2010;362(12):1090-101

33. Pan CW, Wang S, Qian DJ, Xu C, Song E. Prevalence, awareness, and risk factors of diabetic retinopathy among adults with known type 2 diabetes mellitus in an urban community in China. Ophthalmic Epidemiol. 2017;24(3):188-94.

34. Pan CW, Wang S, Wang $\mathrm{P}, \mathrm{Xu} \mathrm{CL}$, Song E. Diabetic retinopathy and health-related quality of life among Chinese with known type 2 diabetes mellitus. Qual Life Res. 2018. https://doi.org/10.1007/s11136-018-1876-6.
35. Song E, Qian DJ, Wang S, Xu C, Pan CW. Refractive error in Chinese with type 2 diabetes and its association with glycaemic control. Clin Exp Optom. 2018:101(2):213-9.

36. American Diabetes Association. Standards of medical care in diabetes-2010. Diabetes Care. 2010;33(Suppl 1):S11-61.

37. Early Treatment Diabetic Retinopathy Study Research Group. Grading diabetic retinopathy from stereoscopic color fundus photographs - an extension of the modified Airlie House classification. ETDRS report number 10. Ophthalmology. 1991;98(5 Suppl):786-806.

38. Rudnisky CJ, Wong BK, Virani H, Tennant MTS. Risk factors for progression of diabetic retinopathy in Alberta First Nations communities. Can J Ophthalmol. 2017;52(Suppl 1):S19-29.

39. Klein R, Knudtson MD, Lee KE, Gangnon R, Klein BE. The Wisconsin Epidemiologic Study of Diabetic Retinopathy: XXII the twenty-five-year progression of retinopathy in persons with type 1 diabetes. Ophthalmology. 2008;115(11):1859-68.

40. Rodrigues TC, Canani LH, Viatroski RS, Hoffmann LH, Esteves JF, Gross JL. Masked hypertension, nocturnal blood pressure and retinopathy in normotensive patients with type 1 diabetes. Diabetes Res Clin Pract. 2010:87(2):240-5.

41. Dosso AA, Leuenberger PM, Rungger-Brandle E. Remodeling of retinal capillaries in the diabetic hypertensive rat. Investig Ophthalmol Vis Sci. 1999;40(10):2405-10

42. Hammes HP, Brownlee M, Edelstein D, Saleck M, Martin S, Federlin K. Aminoguanidine inhibits the development of accelerated diabetic retinopathy in the spontaneous hypertensive rat. Diabetologia. 1994;37(1):32-5.

43. Hinokio Y, Suzuki S, Hirai M, Chiba M, Hirai A, Toyota T. Oxidative DNA damage in diabetes mellitus: its association with diabetic complications. Diabetologia. 1999:42(8):995-8.

44. Wang Q, Pfister F, Dorn-Beineke A, vom Hagen F, Lin J, Feng Y, Hammes HP. Low-dose erythropoietin inhibits oxidative stress and early vascular changes in the experimental diabetic retina. Diabetologia. 2010;53(6):1227-38

45. Kern TS. Contributions of inflammatory processes to the development of the early stages of diabetic retinopathy. Exp Diabetes Res. 2007:2007:95103

46. Vaziri ND, Rodriguez-Iturbe B. Mechanisms of disease: oxidative stress and inflammation in the pathogenesis of hypertension. Nat Clin Pract Nephrol. 2006;2(10):582-93

47. Silva KC, Pinto CC, Biswas SK, de Faria JB, de Faria JM. Hypertension increases retinal inflammation in experimental diabetes: a possible mechanism for aggravation of diabetic retinopathy by hypertension. Curr Eye Res. 2007;32(6):533-41.

48. Calcutt NA, Cooper ME, Kern TS, Schmidt AM. Therapies for hyperglycaemia-induced diabetic complications: from animal models to clinical trials. Nat Rev Drug Discov. 2009;8(5):417-29.

Ready to submit your research? Choose BMC and benefit from

- fast, convenient online submission

- thorough peer review by experienced researchers in your field

- rapid publication on acceptance

- support for research data, including large and complex data types

- gold Open Access which fosters wider collaboration and increased citations

- maximum visibility for your research: over 100M website views per year

At BMC, research is always in progress.

Learn more biomedcentral.com/submissions 